\title{
Time to Work-Opposing Political Rationality with Young Peoples' Experiences of Working in a Mandatory Activation Context in Norway
}

\author{
Heidi Moen Gjersøe ${ }^{1,2}$ (D) Anne Leseth ${ }^{2}$
}

Received: 27 July 2020 / Revised: 7 January 2021 / Accepted: 18 January 2021/ Published online: 12 February 2021

(C) The Author(s) 2021

\begin{abstract}
This paper argues that young people, targeted by activation policies, had several temporal experiences with work that can contribute to broadening our understanding of labour market policy for this group of young people. By drawing on qualitative interviews with young people not in employment, education, or training (NEET) in a Norwegian activation context, and by applying anthropological and sociological concepts on temporality and work time in our analysis, we question how time is constructed and reproduced in the establishment of work relations among this group of people. We argue that political discourses of work inclusion for young adults (NEETs) tend to portray work as a means to an end for inclusion. In doing so, they fail to address the complex temporal dimension of work. We find that young adults have a range of complex experiences where disparity between formal and informal aspects of work becomes visible. The temporal dimension of these experiences and the relativity of speed in getting a job are not experienced in a linear manner but as churning between getting a job, having a job, and losing a job.
\end{abstract}

Keywords Churning $\cdot$ Employment $\cdot$ Temporality $\cdot$ Work inclusion $\cdot$ NEETs $\cdot$ Norway

\section{Introduction}

Labour market participation is a key policy tool for inclusion in society (Eriksen 2010). In particular, a key concern for many European social policy analysts and policymakers

Heidi Moen Gjersøe

heidi.moen.gjersoe@vid.no

1 Faculty of Social Studies, VID Specialized University, Mailbox 184 Vinderen, NO-0319 Oslo, Norway

2 Centre for the Study of Professions, OsloMet - Oslo Metropolitan University, P.O. Box 4 St. Olavs plass, NO-0130 Oslo, Norway 
is how to include young people who are not in employment, education, or training (NEET) in the labour market (Carcillo et al. 2015; Frøyland 2018; OECD 2018). NEETs are a diverse group who vary in terms of their distance from and attitude towards the labour market (Furlong 2006; Yates et al. 2011). NEETs can face multiple barriers to work, including a lack of work experience, health problems, caring responsibilities, and poor qualifications (Sissons and Jones 2012; OECD 2018; Frischsenteret \& Oslo Economics 2019).

Responses to youth unemployment and economic inactivity vary across European welfare states. However, there seem to be similarities between countries such as the Nordic countries and the UK, where one primarily tends to concentrate on individual cases rather than on addressing the structural and societal causes of unemployment and other forms of exclusion (Thompson 2011; Yates et al. 2011).

In Norway, young people aged 18-30 are a target group of labour market policies aiming at activating 'passive' benefit recipients in order to prevent long-term unemployment. In a report on youth in Norway, OECD (2018: 13) states that 'labour market conditions for young people (15-29 years) in Norway are among the most favourable across OECD countries'. However, NEETs in Norway 'tend to be more disadvantaged than in other OECD countries' (ibid.: 9). Norwegian policymakers portray employment as 'personal development, a means to earning a stable income and to participating in a social arena' (Ministry of Labour and Social Affairs 2015-2016: 5). From a political point of view, several solutions to work participation and further education for disadvantaged NEETs have been outlined for young people under 30 in Norway. These might differ in focus, for example, emphasising education or work training (e.g. Frøyland 2018), yet they tend to share the linear aim of getting young people who are out of work into work and keeping them there.

Although labour market participation can be promoted as the ultimate form of community participation, the path to employment may not be straightforward. For instance, a meta-study on the inclusion of vulnerable working young people in the Nordic countries shows the increased use of temporary contracts. On the one hand, this helps the group get to work quickly but, on the other hand, rarely leads to a permanent position. Temporary employment thereby creates 'A and B teams' in the labour market (Hardoy et al. 2016). Compared to unemployed adults, young people, especially those who have not completed education, are more prone to cyclical fluctuations (Hyggen 2013; Paju 2020; Leccardi 2012). In addition, peoples' 'readiness' for work cannot always be fixed by standardised means or even individual assistance (Danneris and Nielsen 2018).

Visibility and retrieval of vulnerable young people's experiences with working life are demanded from a political point of view (see, e.g. Àrnason 2018; OECD 2018). Previous research shows a discordance between work as a social reality and as an abstract political concept (Heen 2008; Holte 2018; Danneris 2018, Anvik et al. 2016). Vulnerable groups' paths into working life point to complex processes (Danneris 2018). In MacDonald et al. (2020), testing policy rhetoric against qualitative case studies revealed a complex reality that left policy assumptions implausible. Danneris and Nielsen (2018) propose to examine discrepancies between policy and lived experiences, that is to say, the experiences that unemployed people have that do not align with the political discourse. This arguably demonstrates that human experiences are overlooked when policies are formulated for the young 
unemployed. A bottom-up view helps us to translate and gain insight into the disparity between young people's life experiences and the auxiliary, bureaucratic, and systemic world (Anvik et al. 2016).

Although there is a huge body of literature addressing the uncertainty, vulnerability, and temporary employment of youths (Leccardi 2005, 2012; Paju 2020; Shildrick et al. 2012; MacDonald et al. 2020 etc.), there are fewer studies that compare the representation of work as stated in political discourse to the lived experiences of work which disadvantaged young NEETs have. Inspired by an analytical approach on temporality, this article investigates discrepancies between young peoples' experiences with working life and the political rationality on work inclusion of this group. Temporality is understood as the infrastructural underpinnings of acceleration, in the sense of 'lived time - structured in particular social, economic, and political contexts' (Wajcman and Dodd 2017: 8). We aim to investigate different notions of time that might be visible in our interviewees' experiences of work compared to activation policies. We ask: How is time constructed and reproduced in the establishment of work relations among young people in an activation context in Norway?

We argue that the Norwegian policy context presents a particular temporal understanding of work, where paid work becomes a subjective goal to be realised throughout the individual's working life. This notion of working life is based on an understanding of the passage of time, which is expressed, for example, in the question 'What are you going to be?'-meaning what work are you going to do? Also in formal work documents such as resumes, where the Latin phrase Curriculum Vitae (CV) has changed from its original meaning of the 'course of life' to referring to a specific structuring of a person's timeline which emphasises ones' formal education, qualifications, and previous occupation(s). Our intention is to explore work as a temporal phenomenon by 'bringing the client back in' (Danneris and Nielsen 2018: 1441).

The article is structured as follows: In the next section, we describe the Norwegian activation context within which we base our study. Subsequently, we present the analytical concepts of time and work before we give an account of the research methods, followed by the findings. Then, we discuss the findings in light of the analytical concepts. Finally, we present a conclusion.

\section{Institutional Context}

Institutional context is an important factor in studies of NEETs. As Holte (2017: 2) argues,

'the NEET concept has different meanings (...) in different contexts'. The concept of NEETs was coined and developed in the UK research in the 1990s (Holte 2017). In the research of MacDonald et al. (2020), class is an important dimension of NEETs and in particular that of the working-class youth. By comparison, Norwegian society can generally be characterised as a more egalitarian society.

In 2017, so-called mandatory activation was implemented as a legislative amendment that obliged the Norwegian welfare and employment agencies (NAV) to make participation in activation measures mandatory for all social assistance (SA) claimants under 30 years old. According to the government, the purpose of the legislative amendment was to strengthen NEETs' opportunities for faster transition to work and 
education (Dahl and Lima 2016; Official Expert Report 2019). Mandatory activation does not only impose requirements on young people but also obliges the NAV office to provide young SA claimants with suitable support such as training centres that provide social support and guidance for job hunting.

Arguably, mandatory activation is structured by a specific understanding of work time. For instance, the young SA claimants may typically be required to show up at a given time at the training centre and stay there for a specific period of time, following a schedule proposed by the case workers there. In this way, the clients are expected to learn the routines of work life as well as punctuality. Hence, time management at the training centre resembles that of contemporary education and work institutions in Norway, which rely on time in terms of calendars, clocks, hours, and minutes (Adam 1995). It is within this temporal, institutional, and political context that the young NEETs' experiences are investigated.

\section{Concepts of Time and Work-a Theoretical Approach}

Paid work is a cultural construct within political and moral contexts: paid work is distinguished from other forms of work by the fact that it has monetary and temporal values that can be measured and standardised. Measurable time, or abstract, spatialised time, has traditionally been opposed to lived time in philosophy, pure duration as Bergson (2001/1913) conceptualised it, that cannot be measured (Paju 2020). Wagner (1986) makes a similar distinction between the passage of time and the presence of time. The passage of time according to Wagner is obvious to everyone; it is how we measure time in hours, calendars, and clocks. He refers to the passage of time as literal time. It is a shared value; we can waste it (e.g. 'gap in a CV'), and we can spend it ('work effectively'). The presence of time, on the other hand, is rather figurative and individual. It is life, and the sum of life's rhythms, activities, and involvements with literal time that give a conventional value to the passage of time (Wagner 1986). To the extent that the presence of time has a meaning of its own, as an autonomous biography, we can speak of it as organic time, Wagner argues.

Wajcman and Dodd (2017) argue that our lives are characterised by a multiplicity of temporal textures and rhythms, depending on what, where, and with whom we are doing things. As suggested by Molotch (2017), all time is relative, for example, what we consider as speedy time is a moral matter as well as an issue of efficiency. People have different expectations of speed in particular organisations, and the people in power tend to take for granted the fast pace for those who serve them (Molotch 2017).

Negrey $(1993,2012)$ and Leccardi (2012) are concerned with the way time and work time are experienced and particularly how time has changed radically over the course of history. Leccardi (ibid.) investigates how young people come to grips with a future that is more and more uncertain, both economically and socially. She argues that young people seem to adapt their own time of life to keep pace with a society characterised by ever more accelerated temporal rhythms. Accelerated time, as a velocity, 'burns up' the dimension of the future enfolding it into an extended present. This has a huge impact on young people's biographical construction, that is, their personal identity. Leccardi (2005: 140) applies the metaphor 'nomads of the present' as appropriate for young peoples’ contemporary biographical trajectories. 
A final conceptualisation of work time encapsulates the temporality of disadvantaged groups in the labour market. Through a critical empirical study from the UK, the belief that poverty and worklessness persist and are 'inherited' in particular families over time is questioned (MacDonald et al. 2020; Shildrick et al. 2012). Through indepth life history interviews with families in extremely deprived neighbourhoods in the UK, this research suggests that neither lack of job opportunities nor a 'culture of worklessness' that dominate policy rhetoric could explain the hardship persisting in these families. Rather, the experience of being out of work is an experience of moving between different low-paid, short-term jobs and receiving benefits on and off. This 'cycling' or 'cycle of disadvantages' (MacDonald et al. 2020), conceptualised as 'churning' (Shildrick et al. 2012), has been largely ignored by governments and labour market policies and counters dominant stories in the UK about welfare dependency.

\section{Research Methods}

MacDonald et al.'s (2020) study shows how qualitative studies are suitable for revealing how the complexity of peoples' lives that is not necessarily compatible with policy assumptions. Furthermore, Holte (2017: 2) argues that 'qualitative research (...) can contribute to a body of knowledge that has mainly been produced by counting NEET young people' and that '[i]ndividual histories of becoming NEET and returning to EET can be complex and lived in ways that counting cannot grasp'.

In line with these arguments, we conducted qualitative interviews within an activation context in order to understand the discrepancies between labour market policies on NEETs and young people's own experiences with work engagement. We conducted 24 semi- structured interviews with 16 young adults aged 19-29 who had, or previously have had, activity obligations with NAV through the mandatory activation scheme. We then reinterviewed 8 of the 16 young adults 7 months later, to get a picture of whether mandatory activation had led to a change in the interviewees' situations in terms of bringing them closer to working life. The young adults were recruited through NAV leaders and supervisors at four medium-sized NAV offices in various municipalities in Southern Norway. The first round of interviews took place in the NAV offices or the training centres. Those who consented to a follow-up interview were asked to suggest a place for the second appointment. One was interviewed in his private home, two at their workplace, another in a café, one in a quiet space at a library, and the last three at the job centre to which they still had access. In this paper, we are concerned with the young peoples' experiences with work across both rounds of interviews to explore how their experiences evolved over time.

Prior to the interview, the interviewees received written information from us about the project: that participation was voluntary, confidential, and would not affect the individual's 'case' with NAV. Consent was given both in writing and verbally. All names are anonymised, and, in some cases, we have changed the gender of the interviewees.

The backgrounds of the interviewees varied. Some had completed secondary school education but had failed to get a job; others had not finished secondary school, often because of difficulties in getting an apprenticeship and dissatisfaction at school. 
Through a combination of active interviewing and descriptive questions, we wanted to get closer to the young adults' own experiences. Active interviewing (Andersen 2006) differs from in-depth interviews in that the researcher refines and directs the conversation towards a specific topic, with the intention of confirming or rejecting certain hypotheses, in this case about experiences of working life (ibid.). In the first interviews, we used an interview guide developed with a purpose of gaining insight into the interviewees' experiences with mandatory activation. This included questions about their previous and current job experiences. In the present article, we have focused specifically on data linked to the interviewees' experience with and perceptions of work. In the second interviews, we posed questions about life changes since the last interview, what a typical day entailed, and about work experiences where relevant. If the interviewees had a job, we asked follow-up questions about work tasks, working conditions, well-being, and so on. All interviews were recorded digitally and transcribed. The transcripts make up the study's data.

We conducted a thematic analysis of the material moving back and forth between induction and abduction, looking for repetitions, similarities, differences, and theory-related material (Ryan and Bernard 2003). The abductive approach is required when 'encountering surprising, anomalous observations that do not fit existing theories and need to come up with a new theory to accommodate these observations' (Tavory and Timmermans 2014: 1). Our analytical work is characterised by three phases of interpretation (e.g. Geertz 1973). First, we read through the interview material in an effort to identify repeating themes related to work experiences brought up by the informants. Second, we drew on our own analytical concepts, such as churning and the passage and presence of time, in an effort to make sense of the participants' interpretations of work experience through our theoretical framework. Finally, we discussed our findings and analysis critically. We identified three themes in the material: 'Getting a job: a slow and linear pathway or a fast and winding road?', 'Having a job: work inclusion or fleeting connections?' and 'Losing a job: the overlooked experiences of loss and retraction'. These themes suggest the churning between jobs, i.e. the movements in and out of working life, as well as how the informants' rhythms in working life, namely, their 'presence of time' depart from the passage of time.

\section{Findings}

\section{Getting a Job: a Slow and Linear Pathway or a Fast and Winding Road?}

In their encounters at the training centres, which represent the political discourse on work inclusion for young NEETs, our interviewees appeared to be presented with a linear pathway to employment: that of applying for and getting a job in order to become self-sufficient. However, the interviewees' own experiences of getting work were quite 'winding' and formed an important point of departure for their motivation to find a new job. Both Siri (27) and Charles (28) have experiences with shortterm job engagements in manual work. Siri has had jobs in a car shop as well as in the kitchen at a nursing home. She described herself as 'hard working'. 
Similarly, Charles presented himself as a man with 'working hands'. At the time of the first interviews, Siri and Charles were both on mandatory activation, while applying for jobs. When Siri arrived at NAVs training centre to participate in job-related activities, she had been excited because she thought they would 'get to work' right away. However, she was a little disappointed:

I was shown into the computer room and requested to sit down and work on my CV and written applications. Shouldn't we work, I thought. But then after a few weeks we started to chop wood to sell. And that is when it became real work.

Siri demonstrates the often conflicting views between young NEETs previous experiences with employment and the training centres' structuring of the pathway towards a job, implying a chronology of specific activities, which involve creating formal written documentation of your job experience, education, and motivation, writing a formal application, and submitting it to all possible vacancies online. However, the temporal formalities of job hunting were experienced as 'time standing still' for the young adults.

In the case of Siri, her expectations of getting a job quickly when entering the activation system were challenged by her experiences with the slow pace of formal job application methods. Even the young people who were successful in getting a job following these formal procedures of writing a CV and submitting applications online emphasised the slowness of this process. Marte (25) says: 'It was the training centre that said I should create a profile with these recruitment agencies. I got a job after three weeks'.

One way of getting a job quickly was through informal networks. Mona (20), who got

a position at her mother's workplace, described this way of getting access to work as easy:

I got a job at the nursing home through my mother. She worked at the local nursing home, so I just called and showed up the next day. I got a job the same day. There wasn't an interview or anything.

Mona was clear that getting a job by making a call or using your social networks could be easy if you were motivated enough. She continued: 'If I am willing to get involved and make the effort to call and when I get there show that I'm interested, then it can be pretty easy'. However, Mona also emphasised that in jobs where you needed more competence, it was not that easy just to show up. There are many jobs that are unattainable for the young people in our study and jobs that require skills, qualifications, and higher education. Some interviewees emphasised the importance of further education in order to access more jobs. Jobs that require something you do not have, such as a driver's licence or impeccable conduct, require in some way more time, in the sense time that is invested in building competence through education and time in writing the application to document the education. The metaphorical 
expression 'time is money', (Lakoff and Johnson 1980:7) could in this context refer to the time spent on education and qualifications in order to secure a better and permanent job.

Another important aspect of getting a job, according to the young people in our study, is to fit in to the job environment. According to Brita (24), you cannot take for granted that more time spent on education will guarantee inclusion at the workplace. She says:

It is not guaranteed that you will get the job, but if you are poorly educated for example, it can help when you show up to show commitment and make a good first impression and show that you are easy to talk to. Yes, it is easier to find out if that person fits that job then. Fitting into the work environment, because they'll see if it is a person who can do the job and fit into the environment. Because you have to fit in too - those who work must go together, if you know what I mean (...). Let's say that the person who has a lot of experience and skills shows up, but is really rude. He is not a good fit for customer care or that type of role then. While the one who has little experience, but of course has some experience, and they get along, then it is a choice that the manager must make. Does he want someone who is easy to talk to and who is good with customers, or does he want someone who knows his stuff and is not so good with customers? (laughter)

Brita's views can summarise a view shared by the young people in our study; getting a job is about establishing a relationship and communication with people in the workplace. These experiences show the winding road into work, which is dependent on who you encounter on your way, how they recognise you as a person, and in what ways you manage to persuade them that you are hardworking. The process of getting a job following a specific 'recipe' is in opposition to the young peoples' experiences of trying to fit in and drawing on their possibilities in their social environment.

\section{Having a Job: Work Inclusion or Fleeting Connections?}

The young people we talked to have different forms of work experience, such as workbased training organised through the training centre, summer jobs, other shorter engagements, or part-time work. Examples include work at a petrol station, in a shop, and in nursing homes, as well as roles including substitute teaching assistant, carpenter, plumber, caretaker, delivery driver, gardener, kindergarten, and farm work.

Judith (22) expressed proudly that she got job training in a shopping centre. 'It was nice to be the chosen one for once', she said, referring to the recruitment process. After the interview with her, we visited her in her workplace, where she was standing in the middle of boxes and displays of cups, glasses, and kitchen appliances. She was wearing perfect make- up and dressed in a black skirt and white shirt. Although she was standing all alone in the shop, with no customers at the time, and we thought she might feel lonely, Judith appeared to be satisfied with just being there, at work, being present.

\footnotetext{
${ }^{1}$ The metaphorical expression 'time is money' is according to Lakoff and Johnson, an expression that structures our everyday activities. Time in our culture is a valuable commodity and a limited resource (Lakoff and Johnson 1980: 8).
} 
A characteristic of many of our interviewees' experiences when they have been offered a job is that the contracts are temporary and short-lived or that they work without a contract. Like many of the others we talked to, Siri (27) has had several different jobs over varied periods of time. When we first interviewed Siri, she had just lost a job as a delivery driver because the company went bankrupt, and she had had seasonal work in the transport sector that meant several months without a job. When we met her again after a few months, she got a job at a store, only 20 min drive away. She said:

Now it's a month at a time, so it's uncertain how long I'll be there ... It's a little scary to just have one month at a time, but I think when I get some income on paper it's a little more secure, because when you have a job it is easier to apply for get another job.

Many appreciated predictable working hours. Thomas (25) had recently had an internship at a nursing home and was given a position as a substitute on call. He emphasises the positive in getting this job. He says: 'Now I have got a job as a regular substitute on call and it is great (..) At least I have a job this month and next month'. Thomas further describes how this system of acquiring shifts within a month works:

You go into an electronic booking system and see which shifts are available. Then you press 'desired shift'. I'm not $100 \%$ sure I'll get the shift, but there's a chance. So when you can apply across eight departments, chances are high (...). Sometimes they also call or send text messages.

Some of the young interviewees describe jobs as small substitutes, down to 30-10\% part-time hour positions. Brita (24) says that even though the training centre 'celebrates' every time one of the participants gets a job, the jobs you get are often not full time. 'It can be $30 \%$ part time permanent but not over $50 \%$ part time'. She elaborates:

I know there are people who are reluctant to apply for these small jobs because it so little. However they need the money after all. So, they have to say yes to such jobs. But they know that it doesn't last long so they know that they have to apply for another, even though they have gotten the job.

While some emphasise the positive sides of having a job at all, others have negative experiences with unreliable employers. Charles says:

I think I have the ability to find bad or unreliable employers (...) those who do not sign a contract or suddenly do not pay wages (...), scam you for money (...). I have been involved in two bankruptcies in companies (...). Unreliable employers have a thousand explanations why you are not getting your money. Those who get a set wage every month should be fucking happy.

Charles' experience shows the disadvantages of fleeting connections with working life. Therefore, having a job cannot necessarily be deemed proof of social inclusion, neither 
on a personal level nor at a more general, policy level. However, for many interviewees, the experience of being in work and receiving a salary was better than not having such experiences at all. Nevertheless, although many of the young adults had positive experiences with short-term work relations, it contributed to short CVs.

\section{Losing a Job: the Overlooked Experiences of Loss and Retraction}

In the everyday life of the young adults in the study, losing a job is also part of everyday life. Some lose or quit the job by their own choice, like Peter (20) who worked as a janitor:

I thought I would like the job, but I didn't. There was just a lot of fuss from the nurses that I had to fix this and that. Replacing light bulbs. This was not what I imagined from being a janitor. So, I quit! Returning home to playing games during the night.

However, Peter emphasised that he has now managed to get another job: 'On Monday I will start another job at a hospital nearby'.

Others quit because the tasks were too physically demanding. Sven (20) had a job of carrying home appliances for customers. He says: 'The job was very hard; I carried washing machines, refrigerators, stuff like that'.

Poor relationships with other employees or failure to fit in can also be a reason to quit. Ove (22) says:

I quit my first job in a car workshop. I was not accepted. (..) got the boring tasks.

(..) it was only those employees who came from the same local area, who were 'from there' that were accepted, only farmers from the local neighbourhood.

Ove points to an interesting tension, as earlier mentioned, in the interviewees' experiences of getting a job, namely, the formal process of job hunting and the importance of fitting in socially. Although one is, as Negrey (2012) points out, employed as an individual, one participates and is included continuously through 'families' or social networks in the workplace.

Not everyone quits because the job is tedious or because they are struggling. It may also be related to structural issues, such as downsizing, bankruptcy, or short contracts. Bjørn (28) says: 'I had a job (...) hanging up sausages eight hours a day. You get bored. But now I miss having a job'. Bjørn got another job afterwards, as a commodity manager. He liked it very much; he drove trucks with pallets of goods from containers. But then he lost the job. He says: 'I hope they call next summer - I couldn't get an extension on my contract because the company was reorganised and downsizing'.

Charles, who was unlucky with some unreliable employers, also had jobs he enjoyed working in, but then the contract expired:

I had a job in a company where there was no nonsense. The salary came as it was supposed to. But my contract expired on Christmas Eve. It was a Friday last year. I was not told if I had a new contract or some new start date. 
In other cases, people lost their job due to offences. Sven lost his job at a car tyre shop because he lost his driver's licence:

I loved working as a car mechanic. But you need the driver's license, right, to be able to drive the cars in and out of the garage. That day I came on the bus and walked into the garage, the lads lost confidence in me. They realised quite quickly the reason that I came by bus and not by car.

Most of the other interviewees also had stories of job termination and unemployment. Eva (23) lost her job in a shop due to staff cuts. She says: 'I had to live off my mum and dad then. After some months they kicked my ass out, and I needed to go to the training centre'. Eva demonstrates how someone can become a 'bouncing ball' between ordinary work, family support, and public employment support in the training centre. There seems to be a discordance between the structural challenges in the labour market - for the group of young adults that our interviewees represent-and the personal efforts, vulnerabilities, and complexities in their lives. Arguably, in the political discourse, unemployment is a state of departure from work inclusion and something to avoid. The policies do not address the complex interpersonal relations that appear during short-term work engagements, such as conflicts, lack of recognition, and satisfaction with the work tasks. These experiences make unemployment the result of deliberate retractions from work life or involuntary loss of work, followed by the acute need to find new work.

\section{Discussion}

The findings outlined in the previous section suggest that the young interviewees' experiences of getting work demonstrate the relativity of speed and the different speed expectations that people might have (Molotch 2017). The disparities between policy discourses and the young adults' experiences are paradoxical. NEETs are seen as passive or 'slow and powerless' in the terms of Wajcman and Dodd (2017) and therefore in need of being activated, whereas public policies appear 'fast and powerful' through interventions such as mandatory activation. However, the opposite of this was experienced by the interviewees in the present study. For the interviewees, the experience of getting a job through an informal network was faster than applying online at the training centre. Therefore, they were the fast ones, and the centres' job hunting activities were slow. Their personal and lived time or 'presence of time' was in conflict with the training centres' 'passage of time' (Wagner 1986).

In terms of Leccardi (2012), the wish for fast job transition may be a way young people construct their own time to keep pace with a society characterised by accelerated temporality. In other words, the young NEETs preoccupation with speed when it comes to getting a job might be seen as their 'response' and their way of trying to fit in to an accelerated society. However, the fast speed does not appear to be an advantage for the young people as they experience quick exits and thereby fleeting connections with working life. Consequently, the young adults' experiences with work show that working life is not just about inclusive practices. Rather, it depends on who you meet, what you do, who you are, and 
under what conditions you get the job. Working life is both a network of social relationships to fit into and various forms of inclusion with formal rights and wage agreements. The mandatory activation as promoted through NAV to the young people in our study may seem to overlook the fact that many of the jobs young people get have a weak form of inclusion. The social dimension of the work may seem integral, but it depends whether one fits in.

An important point is that none of the interviewees' experiences are one-time phenomena, but they appear to happen continuously. Therefore, the policy rhetoric of being included in work life is in practice linked to succeeding at not being excluded from work life. This experience represents a repetitive cycle - churning. With a cyclical understanding of work, the concept of working time is also given new meaning. We argue that situating NEETs' work experiences within a cyclical rather than a linear timeline strengthens the understanding of the temporal dimension of work inclusion. Formal job requirements, such as resumes, require a specific structuring of a person's formal education, qualifications, and previous work experience. The findings bring new light to the widely used expression 'gap in the CV', not only as a barrier for employment but as a very real experience young adults have of the distance between their expected timeline and their actual course of life so far. To put it differently, we suggest that a resume as a formal document represents part of the public discourse on qualification for work that fails to grasp aspects of life that do not follow a linear timeline through education, work, and employment. Perhaps the young adults' experiences of churning work time are also something that can reflect their life situation generally, namely, the instability, lack of belonging, and broken relationships. This view draws attention away from a work life where this group cannot be offered stable work. The policy's discourses about work and the importance of getting closer to working life obscure the reality of working life that young people encounter in the labour market.

For young adults, working time is their description of the timeframe in which they actually have work (e.g. over a month or a half year), given that their involvement and roles are often temporary contracts, summer jobs, job training, part-time positions, or short-term substitutes. The working hours are based on a fundamental uncertainty as to how far one should get involved. This finding resonates with Negrey's (1993) argument in that irregular work implies unpredictable time. Someone other than the worker controls the work schedule. In our study, this is typical in the young adults' description of their workday. They need to step in at short notice, or they might need to work fewer or more hours than planned. Personal time management is difficult for people with irregular work schedules, and this is reflected in how they use their time off (e.g. 'waiting' for more work, ensuring they are available). Irregular work schedules, Negrey (1993) argues, curb personal autonomy.

The central finding that the young adults' experiences of getting, having, and losing a job is framed by a structural uncertainties of having to rely on an informal network, short- term contracts, and loss of jobs. In other words, the interviewees' experiences do not only say something about their connection to working life but also about the working life they are connected to. The working life they are a part of is characterised by temporary employment, high penetration, and high demand for flexible and often unskilled labour. Getting a job is far from synonymous with full-time work. Consequently, while the political discourse focuses on unemployment and getting a job, the 
reality of interpersonal conflicts, lack of recognition, and short-term contracts is not visible in the policies for NEETs.

Activation policies and the context of mandatory activation promote both a particular understanding of work and work time, and at the same time it implies specific cycles of disadvantages. The cycle of getting, having, and losing a job may perhaps represent an invisible border zone to working life. Young NEETs experience work time with a continuous circularity. While activation policies follow a linear process-based time schedule, cycles of disadvantages remain a blind spot in activation work. Therefore, although public employment support is intended to help young people to get away from 'benefit dependency', the linear temporality in this support may in fact underpin the young people's position as marginalised.

\section{Conclusion}

Our presumption for this research was that political discourses of work inclusion for young adults (NEETs) tend to portray work as a means to an end for inclusion and fail to address the complex temporal dimension with work. We find that young adults have a range of complex experiences where discordance between formal and informal aspects of work becomes visible. The temporal dimension of these experiences is not in terms of a linear structure of getting a job but as churning between getting a job, having a job, and losing a job. In the overall policy context, work is promoted as a general and abstract phenomenon in which the social and cultural context that work is embedded in is often not thematised. Therefore, in the face of the Norwegian welfare services and enactment of mandatory activation, political ideas about work are contested in light of the young adults' various experiences with work in everyday life. From the young adults' point of view, the path from unemployment to employment is not a straight path, it is a winding road in which the passage and presence of time is intertwined.

Acknowledgements The authors are grateful for the comments received by Bjørn Hallstein Holte as well as three anonymous referees.

Funding Open access funding provided by OsloMet - Oslo Metropolitan University. This study was supported by the Research Council of Norway, Grant/Award Number: 257603.

Data availability The data that support the findings of this study are available from the corresponding author upon reasonable request.

Code Availability Not applicable

\section{Declarations}

Conflict of Interest The authors declare no competing interests.

Open Access This article is licensed under a Creative Commons Attribution 4.0 International License, which permits use, sharing, adaptation, distribution and reproduction in any medium or format, as long as you give appropriate credit to the original author(s) and the source, provide a link to the Creative Commons licence, and 
indicate if changes were made. The images or other third party material in this article are included in the article's Creative Commons licence, unless indicated otherwise in a credit line to the material. If material is not included in the article's Creative Commons licence and your intended use is not permitted by statutory regulation or exceeds the permitted use, you will need to obtain permission directly from the copyright holder. To view a copy of this licence, visit http://creativecommons.org/licenses/by/4.0/.

\section{References}

Adam B (1995) Timewatch: the social analysis of time. Polity, Cambridge

Andersen SS (2006) Aktiv informantintervjuing. Norsk Statsvitenskapelig Tidsskrift 3:279-298

Anvik CH, Gustavsen K, Wrede-Jäntti M (2016) Hverdagsliv som erfaringsnært perspektiv på unges sårbare livssituasjon. In: Wulf-Andersen T, Follesø R, Olsen T (eds) Ungeudenforskab og social forandring: nordiske perspektiver, Frydelund Academic, Fredriksberg, pp 119-138

Bergson H (2001/1913) Time and free will: an essay on the immediate data of consciousness. Dover Publications, New York

Carcillo S, Fernández R, Königs S, Minea A (2015) NEET youth in the aftermath of the crisis: challenges and policies. OECD, Paris

Dahl ES, Lima IAÅ (2016) Krav om å stå opp om morra n: virker det? Arbeid og velferd 3, https://www.nav. no/no/nav-og-samfunn/kunnskap/analyser-fra-nav/arbeid-og-velferd/arbeid-og-velferd/krav-om-a-staopp-om-morra-n-virker-det. Accessed 15/12/2020

Danneris S (2018) Ready to work (yet)? Unemployment trajectories among vulnerable welfare recipients. Qual Soc Work 17(3):355-372. https://doi.org/10.1177/1473325016672916

Danneris S, Nielsen MH (2018) Bringing the client back in: a comparison between political rationality and the experiences of the unemployed. Social Policy and Administration 52(7):1441-1454. https://doi.org/10. $1111 /$ spol.12386

Eriksen TH (2010) Samfunn. Universitetsforlaget, Oslo

Frischsenteret \& Oslo Economics (2019). Årsaker til økt tilstrømming til uføretrygd blant unge. Delrapport: Psykiske helseproblemer blant unge - En litteraturgjennomgang. Department for work and social welfare (ASD), Oslo

Frøyland K (2018) Vital tasks and roles of frontline workers facilitating job inclusion of vulnerable youth. Eur J Soc Work 22(4):563-574. https://doi.org/10.1080/13691457.2018.1423547

Furlong A (2006) Not a very NEET solution: representing problematic labour market transitions among early school-leavers. Work Employ Soc 20(3):553-569. https://doi.org/10.1177/0950017006067001

Geertz C (1973) The Interpretations of Cultures. Basic Books, New York

Hardoy I, Røed K, von Simson K, Zhang T (2016) En komparativ analyse av effekter av innsats for å inkludere utsatte unge i arbeid i norden. Research Report. Institutt for Samfunnsforskning, Oslo

Heen H (2008) Om bruken av begrepet arbeid. Sosiologi i dag 38(4):29-50, Sofiemyr: Novus Forlag

Holte BH (2018) Counting and meeting NEET young people: methodology, perspective and meaning in research on marginalized youth. Young 26(1):1-16. https://doi.org/10.1177/1103308816677618

Hyggen C (2013) Unge i og utenfor arbeidsmarkedet i Norden. Søkelys på Arbeidslivet 30(4):357-377. Idunn, Norway

Lakoff G, Johnson J (1980) Metaphors we live by. University of Chicago Press, Chicago

Leccardi C (2005) Facing uncertainty. temporality and biographies in the new century. Nordic J Youth Res 12(2):123-146 https://doi.org/10.1177/1103308805051317

Leccardi C (2012) Young people's representations of the future and the acceleration of time: a generational approach. Diskurs Kindheits-und Jugendforschung/Discourse. J Childhood Adolesc Res 7(1):59-73

MacDonald R, Shildrick T, Furlong A (2020) 'Cycles of disadvantage' revisited: young people, families and poverty across generations. J Youth Stud 23(1):12-27. https://doi.org/10.1080/13676261.2019.1704405

Ministry of Labour and Social Affairs (2015-2016) White Paper no 33 NAV i en ny tid - for arbeid og aktivitet

Molotch H (2017) "Just time" and the relativity of speed. In: Wajcman J, Dodd N (eds) (2017) The sociology of speed. Digital, organizational, and social temporalities. Oxford University Press, Oxford, pp 117-130

Negrey C (1993) Gender, time and reduced work. State University of New York Press, Albany

Negrey CL (2012) Work time. Conflict, control and change. Polity, Cambridge

OECD (2018) Investing in Youth. OECD Publishing, Paris, Norway. https://doi.org/10.1787/24126357 
Official Expert Report (2019) NOU 2019:7 Arbeid og inntektssikring - tiltak for økt sysselsetting. Ministry of Labour and Social Affairs, Oslo

Paju E (2020) Futures in action: embodied or empty futures in youth activation workshops. Time Soc 29(3): 637-658. https://doi.org/10.1177/0961463X19842474

Ryan GW, Bernard HR (2003) Techniques to identify themes. Field Methods 15(1):85-109. https://doi.org/ $10.1177 / 1525822$ X02239569

Shildrick T, MacDonald R, Webster C, Garthwaite K (2012) Poverty and insecurity: life in low-pay, no-pay Britain. Policy Press, Bristol

Sissons P, Jones K (2012) Lost in transition? The changing labour market and young people not in employment, education or training. The Work Foundation, London

Tavory I, Timmermans S (2014) Abductive analysis. Theorizing Qualitative Research. TheUniversity of Chicago Press, London

Thompson R (2011) Individualisation and social exclusion: the case of young people not in education, employment or training. Oxford Rev Educ 37(6):785-https://doi.org/10.1080/03054985.2011.636507

Wagner R (1986) Symbols that stands for themselves. University of Chicago Press, Chicago

Wajcman J, Dodd N (2017) The sociology of speed. Digital, Organizational, and Social Temporalities. Oxford University Press, Oxford

Yates S, Harris A, Sabates R, Staff J (2011) Early occupational aspirations and fractured transitions: a study of entry into 'NEET' status in the UK. J Soc Policy 40(3):513-534. https://doi.org/10.1017/ S0047279410000656 